\title{
Site-Directed Mutagenesis Combined with Oxidative Methionine Labeling for Probing Structural Transitions of a Membrane Protein by Mass Spectrometry
}

\author{
Yan Pan, ${ }^{\mathrm{a}}$ Leonid Brown, ${ }^{\mathrm{b}}$ and Lars Konermann ${ }^{\mathrm{a}}$ \\ ${ }^{a}$ Department of Chemistry, University of Western Ontario, London, Ontario, Canada \\ ${ }^{b}$ Department of Physics, University of Guelph, Guelph, Ontario, Canada
}

\begin{abstract}
Exposure of the membrane protein bacteriorhodopsin (BR) to SDS induces partial breakdown of the native conformation. The exact structural properties of this SDS state remain a matter of debate, despite its widespread use in BR folding experiments. The current work employs hydroxyl radical $(\cdot \mathrm{OH})$ labeling in conjunction with mass spectrometry (MS)-based peptide mapping for probing the solvent accessibility of individual BR segments in the presence of SDS. Previous work revealed methionine sulfoxide formation to be the dominant oxidative pathway. Those data suggested extensive unfolding of helices A and D in SDS. Unfortunately, the lack of Met residues in helices $\mathrm{C}$ and $\mathrm{F}$ implies that no direct information on the behavior of the latter two elements could be obtained. Here, we address this problem by employing two variants with additional Met residues, L93M (helix C) and V179M (helix F). The oxidation behavior of the resulting 11 methionines can be grouped into three categories: (1) extensively labeled both in native BR and in SDS (loop residues M32, M68, and M163); (2) protected in the native state but not in SDS (M20, M118); (3) always protected (M56, M60, M93, M145, M179, M209). These data show that a solvent-inaccessible core is retained in SDS. This core consists of partially intact helices B, C, E, F, and G. The termini of these helices are highly dynamic and/or unraveled, particularly on the cytoplasmic side. Overall, this work demonstrates how the use of engineered $\mathrm{OH}$ labeling sites can provide insights into structural properties of membrane proteins. (J Am Soc Mass Spectrom 2010, 21, 1947-1956) (c) 2010 Published by Elsevier Inc. on behalf of American Society for Mass Spectrometry
\end{abstract}

$\mathrm{M}$ ass spectrometry (MS) plays a central role for a wide range of structural biology applications $[1,2]$. Unlike X-ray crystallography and NMR spectroscopy, MS does not provide atomicallyresolved structural information. However, the low-tomedium resolution obtainable by MS is highly valuable for systems that are difficult to study by other approaches. For example, the direct electrospray ionization (ESI)-MS analysis of large macromolecular assemblies provides insights into binding stoichiometries [3] and affinities [4]. The degree of multiple charging during ESI reflects the protein compactness and surface area in solution [5]. Amide hydrogen/deuterium exchange (HDX)/MS allows probing the hydrogen bonding network of proteins [6]. Chemical cross-linking yields interand intramolecular distance constraints $[7,8]$.

Covalent labeling represents another important MSbased structural approach. Exposure of a protein to a hydrophilic reactive probe induces chemical modifications in solvent accessible areas, whereas regions that

Address reprint requests to Dr. L. Konermann, Department of Chemistry, The University of Western Ontario, London, ON, N6A 5B7, Canada. E-mail: konerman@uwo.ca are sterically shielded do not get labeled. A variety of tagging agents have been developed, some of which react only with specific types of side chains, whereas others are less selective. The locations of the resulting modifications and the extent of labeling may be probed by peptide mapping and liquid chromatography (LC) with on-line ESI-MS/MS [2, 9-12]. Hydroxyl radical $(\cdot \mathrm{OH})$ is an interesting covalent probe due to its small size and high reactivity. Of the many methods for generating $\cdot \mathrm{OH}$ [13-20], the photolysis of $\mathrm{H}_{2} \mathrm{O}_{2}$ by a pulsed UV laser [21-23] is particularly convenient. The microsecond $\cdot \mathrm{OH}$ lifetime implies that this photochemical technique is free of oxidation-induced artifacts if the measurements are conducted under single-exposure conditions [21, 24, 25].

Despite their physiologic and pharmaceutical importance, membrane proteins represent a class of biomolecules that poses considerable experimental challenges [26]. Membrane proteins are prone to aggregation once removed from their natural lipid bilayer. Thus, the application of X-ray and NMR techniques to membrane proteins continues to be problematic. As a result, these species are hugely under-represented in structural databases when compared to water-soluble proteins [27]. 
Numerous MS-based covalent labeling experiments have been conducted on membrane proteins [28, 29], e.g., for topologic investigations [30], as well as for monitoring conformational changes [29, 31-34] and binding interactions [35-37].

Bacteriorhodopsin (BR) is the main component in the purple membrane of the archaebacterium Halobacterium salinarum. It represents one of the few membrane proteins for which high-resolution structural data are available [38], and it has become an important test system for the development of novel analytical strategies [39]. The 248 amino acid polypeptide chain of native BR folds into seven transmembrane helices (A-G), which are connected by extra-membrane loops (Figure 1). The protein forms a central pocket that accommodates a retinal chromophore. This prosthetic group is linked to K216 of helix G via a protonated Schiff base. From a biophysical point of view, BR is important not only because of its intriguing photocycle [40, 41], but also because it is one of only a handful of membrane proteins that can be folded in vitro [42-48].

While it is not straightforward to obtain structural data for native membrane proteins, it is even more challenging to gain information on the behavior of these systems under non-native conditions. Yet, semi-denatured proteins play important biological roles during folding, assembly, and amyloidogenesis [49, 50], for ligandbinding [51], and for translocation [52]. Therefore, the development of experimental approaches for exploring the properties of non-native membrane proteins is an important task.

Sodium dodecyl sulfate (SDS) is an anionic detergent that is widely used as protein denaturant due to its powerful dissociation and solubilization properties [53].

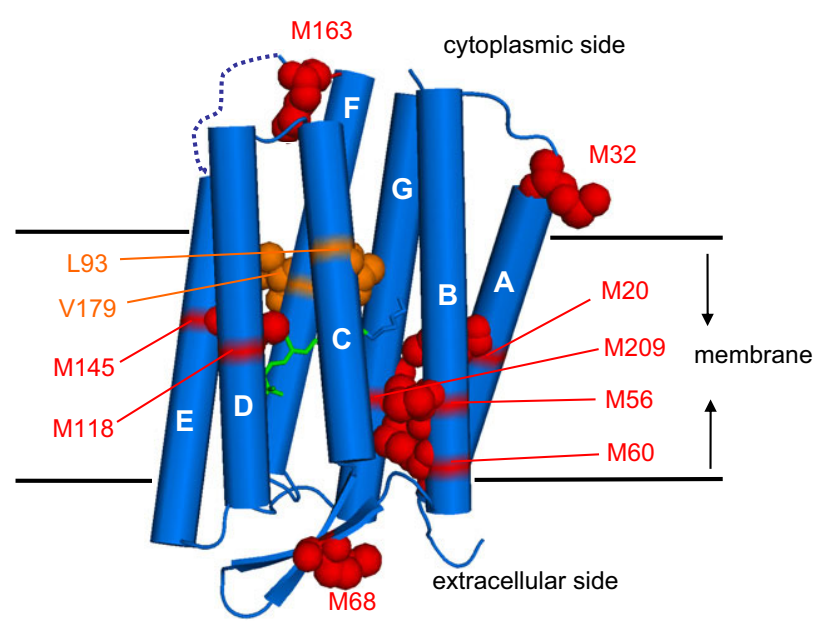

Figure 1. X-ray structure of bacteriorhodopsin (BR, pdb 1C3W) [38] with its seven transmembrane helices (A-G). The nine methionine residues of the wild type protein are highlighted in red, and the retinal chromophore is depicted in green. Also shown are leucine 93 and valine179 (orange), which were converted to methionines for some of the experiments of this work. A brief segment of the EF loop for which no structural data are available is shown as dotted line.
However, SDS-denatured membrane proteins often retain significant residual structure, in fact, some $\alpha$-helical elements may even be stabilized to a certain extent [45, 53]. SDS-solubilized BR often serves as a starting point for folding studies [54]. A comprehensive characterization of this state is therefore crucial for deciphering the mechanism by which BR refolds and inserts into the lipid bilayer. Unfortunately, considerable uncertainties continue to exist regarding the structural properties of SDS-denatured BR. For example, the extent to which individual helices become unraveled in SDS remains a matter of debate $[55,56]$.

Our group has previously explored the properties of native and SDS-denatured BR by $\cdot \mathrm{OH}$ labeling [56]. In contrast to the behavior observed for many watersoluble proteins, it was found that oxidative modifications occurred exclusively at methionine residues, resulting in methionine sulfoxide (MetO) formation [56, 57]. While this chemical selectivity is somewhat surprising, it is in line with the fact that sulfur-containing residues are generally most prone to oxidation $[15,58]$ (BR does not contain cysteine). Also, the exclusive labeling of Met residues greatly facilitates the quantitative analysis of oxidation patterns. Like many other membrane proteins, BR is rich in methionine, containing a total of 9 Met residues. Six of these are buried in transmembrane regions of native BR (M20 [helix A], M56/M60 [B], M118 [D], M145 [E], and M209 [G]), whereas M32, M68, and M163 are located in solventaccessible loops (Figure 1). $\mathrm{OH}$ exposure of native BR causes extensive labeling of the three solvent-accessible Met residues, whereas those inside the membrane are largely protected [57]. This behavior validates the use of oxidative Met labeling as a tool for probing the solvent accessibility of individual BR segments.

SDS solubilization results in marked changes of the BR oxidation pattern, with M20 [A] and M118 [D] becoming significantly more solvent accessible [56]. Based on those $\cdot \mathrm{OH}$ labeling data and the results of UV-Vis and fluorescence experiments we proposed a structural model of SDS-denatured BR. SDS induces hydrolytic retinal loss and release of the chromophore into the solvent. We suggested that this step is accompanied by collapse of the chromophore binding pocket and partial unfolding/extrusion of helices A and D. In contrast, helices B, C, E, F, and G were proposed to remain largely intact, although some unraveling at the helix termini could not be excluded [56].

A conceptual difficulty of our earlier proposal [56] is the lack of methionine residues in helices $\mathrm{C}$ and $\mathrm{F}$ of wild-type (wt) BR. Hence, ideas regarding the intactness of these two helices in SDS had to be based on indirect evidence from fluorescence spectroscopy, rather than direct solvent accessibility data. The current work addresses this problem by conducting oxidative labeling experiments on BR variants that were engineered to possess additional methionine residues in either helix C (L93M) or helix F (V179M). In this way, each helix is covered by at least one oxidative labeling 
site. Exposure of these variants to $\cdot \mathrm{OH}$ provides the first direct confirmation that the central portions of helices $C$ and $\mathrm{F}$ indeed remain shielded from the solvent in SDS-denatured BR. From a general perspective, the current study demonstrates how the combination of oxidative labeling and protein engineering can provide insights into structural aspects of membrane proteins.

\section{Experimental}

\section{Proteins and Reagents}

Sequencing-grade modified trypsin was purchased from Promega (Madison, WI, USA). The acid-labile surfactant RapiGest SF was obtained from Waters (Milford, MA, USA). SDS, ammonium bicarbonate, sodium phosphate, potassium phosphate, and formic acid were from Sigma (St. Louis, MO, USA). All chemicals were used as received. Purple membranes from $H$. salinarum expressing wt BR were harvested and purified by sucrose gradient centrifugation as described [57]. Cell lines expressing the L93M and V179M variants were a generous gift from Janos K. Lanyi (University of California at Irvine). Purification of these mutant proteins was performed as for wt BR. The expected masses of intact wt BR, L93M BR, and V179M BR based on the amino acid sequences (including retinal) were calculated as 27,050 $\mathrm{Da}$ [59], 27,068 $\mathrm{Da}$, and 27,082 $\mathrm{Da}$, respectively. Low-temperature SEC/ESI-MS analysis [60] of all three protein variants confirmed these theoretical mass values to within $\pm 1 \mathrm{Da}$. The amino acid substitutions of the two mutant proteins were further verified by tryptic peptide mapping and ESI-MS/MS (data not shown). Protein solutions for laser-induced oxidative labeling were adjusted to $\mathrm{pH} 7$ using $10 \mathrm{mM}$ sodium phosphate buffer. Native BR samples were analyzed as intact purple membrane suspensions [57]. In the case of denatured BR the buffer contained $0.2 \%$ (wt/vol) SDS. All samples were sonicated in a water bath (FS60; Fisher Scientific, Ottawa, ON, Canada) for $15 \mathrm{~min}$, followed by equilibration at room-temperature for six hours. UV-Vis absorption measurements were carried out on a Cary 100 spectrophotometer (Varian, Mississauga, ON, Canada) at a protein concentration of $10 \mu \mathrm{M}$ at room temperature, using protein-free solutions as blanks.

\section{Laser-Induced Oxidative Labeling}

Covalent labeling of BR mutants was performed in a manner similar to that described previously $[56,57]$. Briefly, solutions with $12 \mu \mathrm{M}$ protein, $0.15 \% \mathrm{H}_{2} \mathrm{O}_{2}$, and $15 \mathrm{mM}$ glutamine were pumped through a $100 \mu \mathrm{m}$ i.d. flow capillary made of fused silica (TSP100170; Polymicro Technologies, Phoenix, AZ, USA) at $40 \mu \mathrm{L} \mathrm{min}{ }^{-1}$. Initial labeling experiments (not shown) employed $0.05 \% \mathrm{H}_{2} \mathrm{O}_{2}$, as in our earlier work on wt BR [57]. Because the oxidation levels obtained under those conditions were quite low, the peroxide content was in- creased to $0.15 \%$ for this study. The origin of this different behavior is not clear, but possibly the samples used here contained a higher concentration of lipids and/or other bio-organic compounds that can act as radical scavengers [61, 62]. A KrF excimer laser (GAM EX 100/125; Orlando, FL, USA) producing 18 ns pulses at $248 \mathrm{~nm}, 16 \mathrm{~Hz}$, and $63 \mathrm{~mJ}$ was used for generating . $\mathrm{OH}$ by $\mathrm{H}_{2} \mathrm{O}_{2}$ photolysis [21]. Capillary outflow aliquots of $60 \mu \mathrm{L}$ were collected in microcentrifuge tubes containing $10 \mu \mathrm{L}$ of $200 \mathrm{mM}$ free methionine and $25 \mu \mathrm{L}$ of $1 \mu \mathrm{M}$ catalase ( $\mathrm{pH} 7$ ) for deactivating residual $\mathrm{H}_{2} \mathrm{O}_{2}$ and other oxidizers that might cause spurious secondary labeling $[63,64]$. To ensure catalase activity, the collection tube also contained $150 \mu \mathrm{L}$ water in the case of SDS experiments. Background oxidation (control) samples were generated in the same way, with the exception that the laser was switched off.

\section{Tryptic Digestion}

Labeled and control samples were lyophilized. Subsequently, the dry powder was dissolved in $35 \mu \mathrm{L}$ of 100 $\mathrm{mM}$ ammonium bicarbonate buffer $(\mathrm{pH}$ 8) containing $0.1 \%$ (wt/vol) RapiGest. For native BR, the resulting solutions were directly digested for $24 \mathrm{~h}$ at $37^{\circ} \mathrm{C}$ using a 1:20 (wt/wt) trypsin:protein ratio. For SDS samples, 5 $\mu \mathrm{L} 1.0 \mathrm{M}$ potassium phosphate buffer $(\mathrm{pH}$ 8) was added. The resulting detergent precipitate was removed by centrifugation at $13,000 \mathrm{~g}$ for $5 \mathrm{~min}$. The supernatant was digested as described above. All digests were flash-frozen in liquid nitrogen and stored at $-80^{\circ} \mathrm{C}$.

\section{LC/ESI-MS}

After oxidative labeling, protein digests were analyzed on a Waters Q-TOF Ultima API mass spectrometer equipped with a Z-spray ESI source. Spectra were acquired in positive ion mode at a sprayer voltage of 3 $\mathrm{kV}$ and a desolvation temperature of $250^{\circ} \mathrm{C}$. The mass spectrometer was coupled to a Waters Acquity UPLC employing a $1.7 \mu \mathrm{m} \mathrm{C18} \mathrm{BEH} 130$ column $(2.1 \mathrm{~mm} \times$ $100 \mathrm{~mm}) .10 \mu \mathrm{L}$ portions of digested sample were loaded onto the UPLC column without prior RapiGest removal using an autosampler. LC separations were carried out at $100 \mu \mathrm{L} \mathrm{min}{ }^{-1}$ and $40{ }^{\circ} \mathrm{C}$. Solvent A was $0.1 \%$ aqueous formic acid, and solvent B consisted of $50: 50$ (vol/vol) acetonitrile/isopropanol with $0.065 \%$ formic acid. A linear gradient was run from 3\% to $5 \%$ B in $4 \mathrm{~min}$, then from $12 \%$ to $38 \% \mathrm{~B}$ in $7 \mathrm{~min}, 38 \%$ to $62 \%$ $\mathrm{B}$ in $2 \mathrm{~min}, 62 \%$ to $80 \% \mathrm{~B}$ in $12 \mathrm{~min}$, and ultimately from $80 \%$ to $100 \%$ B in 5 min. Most peptides eluted between 6 and $25 \mathrm{~min}$. Peptide identities were confirmed by MS/MS in data-dependent acquisition mode, employing collision-induced dissociation (CID) in an Ar-filled hexapole cell. Oxidation sites were determined in offline MS/MS experiments, by collecting the UPLC eluent in a 96-well plate. These samples were then injected into the mass spectrometer using a TriVersa 
NanoMate (Advion, Ithaca, NY, USA) chip-based ion source.

\section{Data Analysis}

The degree of Met oxidation for each peptide can be reported as the "fraction unmodified," $F_{u}$, defined as

$$
F_{u}=\frac{A_{u}}{A_{u}+A_{a x}}
$$

where $A_{u}$ and $A_{o x}$ are the integrated peak areas of the unmodified species and its oxidation product(s), respectively, in the mass spectra. Integration was carried out using Microsoft Excel, taking into account protonated as well as sodiated signals of every peptide. The measured data were corrected for background oxidation using the relationship [56] $F_{u}{ }^{\text {corr }}=F_{u}{ }^{a p p} / F_{u}{ }^{\text {bgr }}$ where $F_{u}{ }^{a p p}$ is the apparent $F_{u}$, determined by applying eq 1 directly to data obtained after $\cdot \mathrm{OH}$ exposure. $F_{u}{ }^{b g r}$ represents the $F_{u}$ of corresponding control samples that were not irradiated. $F_{u}{ }^{\text {corr }}$ reflects the actual extent of laser-induced labeling, corrected for background oxidation. All $F_{u}{ }^{\text {corr }}$ values reported in this work represent an average of at least three independent data points, each with its own background correction. Error bars reflect the maximum deviation from the average value.

\section{Hydrogen/Deuterium Exchange}

Isotope exchange was initiated by mixing the BR samples with $\mathrm{D}_{2} \mathrm{O}$-based buffer at room temperature in a 1:4 volume ratio. Aliquots were removed at various time points, followed by acid quenching and flash freezing [60]. Zero time point controls $\left(m_{0}\right)$ were performed by exposing the samples to a mixture of labeling and quenching buffer. Maximally deuterated samples $\left(m_{100}\right)$ were prepared by incubation in $80 \% \mathrm{D}_{2} \mathrm{O}$ with $0.4 \%$ SDS at $\mathrm{pH} 11.8$ and $40{ }^{\circ} \mathrm{C}$ for $30 \mathrm{~h}$. Following isotope exchange, intact protein samples were analyzed by size exclusion chromatography/ESI-MS using a BioSuite, 4 $\mu \mathrm{m}$ UHR SEC, $4.6 \mathrm{~mm} \times 300 \mathrm{~mm}$ (Waters) column. Relative deuteration levels were determined using the expression

$$
\text { deuteration level }=\left(m-m_{0}\right) /\left(m_{100}-m_{0}\right)
$$

where $m$ is the mass of the protein, and $m_{0}, m_{100}$ are the values of the corresponding controls. Details of the HDX procedure used here have been provided previously [60].

\section{Results and Discussion}

\section{Structural Integrity of BR Mutants}

For gaining a better understanding of the BR structural behavior, two variants (L93M and V179M) were examined that provide potential oxidation sites in helices $\mathrm{C}$ and $\mathrm{F}$, respectively. A meaningful mutational analysis requires that the altered amino acids do not induce major changes to the native protein structure. To minimize any such perturbations, we examined the two substitutions in separate protein constructs, rather than using a double mutant.

UV-Vis absorption spectroscopy provides a sensitive probe of the retinal environment [56, 65]. Native V179M BR exhibits an absorption maximum at $568 \mathrm{~nm}$, identical to that of the wt protein. The spectrum of native L93M BR is slightly blue shifted to $552 \mathrm{~nm}$ (Figure 2a). This different behavior is consistent with the fact that L93 is in direct contact with the 13-methyl group of the chromophore, whereas V179 points away from the retinal binding pocket (Figure 1). Infrared spectroscopic measurements demonstrated that the BR photocycle is moderately affected by the L93M substitution, but no perturbations of the overall protein structure were
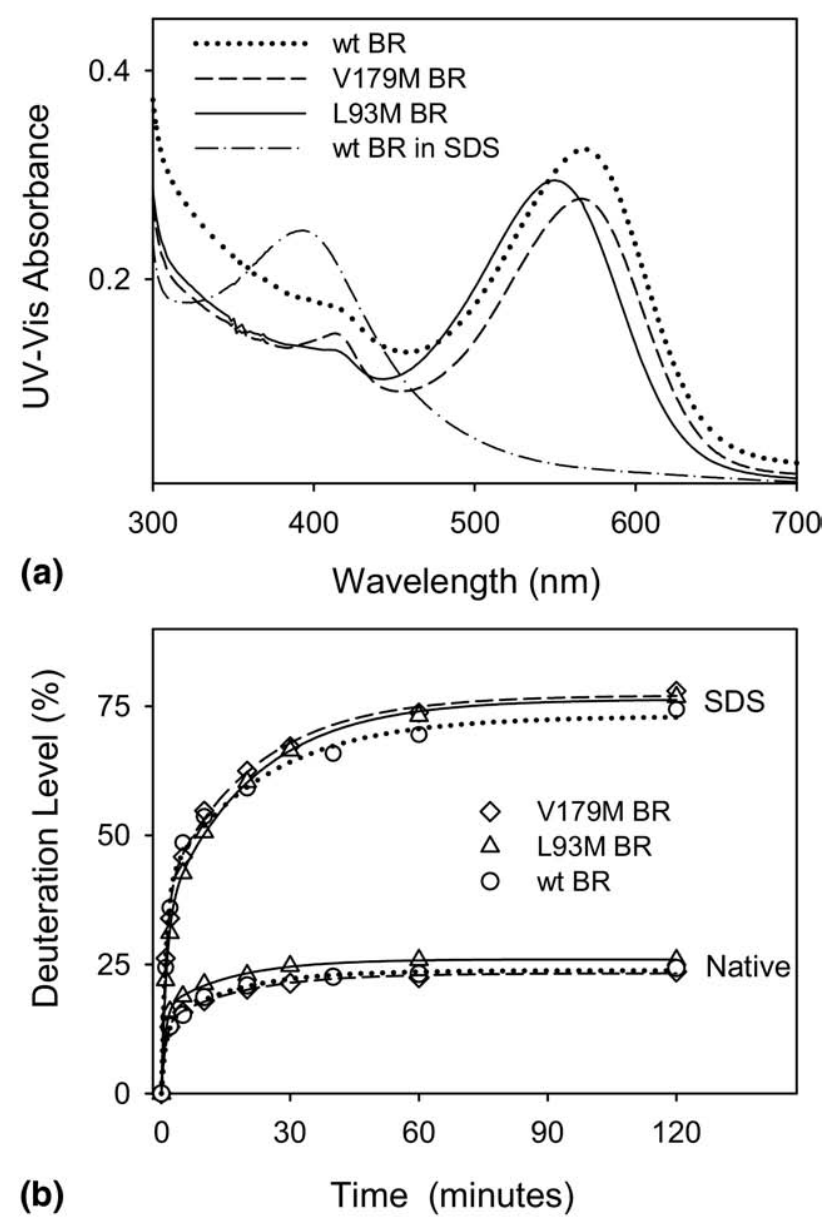

Figure 2. (a) UV-Vis absorption spectra of native wt (wild type) BR, L93M BR, and V179M BR. Also shown is the spectrum of SDS-denatured wt BR. (b) HDX kinetics of wt BR, L93M BR, and V179M BR under native solvent conditions, and after SDS denaturation. Lines in panel (b) are biexponential fits. HDX data for each time point represent averages of two or three independent measurements. 
reported [66, 67]. When solubilized in SDS, wt BR as well as the two mutants exhibit an absorption maximum at $392 \mathrm{~nm}$, while the band in the $560 \mathrm{~nm}$ range disappears (depicted in Figure 2a for wt BR). This behavior reflects hydrolysis of the Schiff base linkage between retinal and K216, concomitant with release of the chromophore into the solvent $[56,65]$.

The HDX behavior of native wt BR reflects a high degree of protection. Only $24 \%$ of the 236 amide hydrogens undergo exchange within $120 \mathrm{~min}$. SDS denaturation dramatically enhances the degree of HDX, resulting in $75 \%$ deuteration within the same time interval (Figure $2 \mathrm{~b}$ ). A detailed analysis of these isotope labeling data is beyond the scope of the current work and has been reported elsewhere [60]. Unfortunately, applying the traditional proteolytic digestion/HDX-MS approach to BR is difficult [68], and hence we were unsuccessful in analyzing the BR deuteration behavior in a spatially resolved manner. The pertinent question explored here is in how far the structure and dynamics of the V179M and L93M variants are different from those of wt BR. Figure $2 b$ reveals that all three forms exhibit very similar HDX kinetics under native conditions, as well as after SDS exposure.

Overall, our UV-Vis data (Figure 2a) as well as the HDX results of Figure $2 b$ strongly suggest that the L93M and V179 substitutions are largely benign. In other words, the BR structure does not seem to be significantly affected by either replacement. This assertion is further supported by Trp fluorescence experiments, which yielded spectra that were virtually indistinguishable for L93M, V179M, and wt BR, both under native conditions and in SDS (data not shown).

\section{Oxidative Labeling}

Trypsinolysis of L93M BR and V179M BR resulted in various peptides. The protein fragments with the highest signal intensities are listed in Table 1 , yielding a sequence coverage of $97 \%$. Newly introduced methionines for the L93M and V179M variants are located in peptides T5 and T10-11, respectively. Just as in our previous studies on wt BR [56, 57], MS/MS revealed that $\cdot \mathrm{OH}$ exposure resulted in MetO formation (corresponding to a +16 Da mass shift) as the only detectable type of covalent modification for any of the conditions studied here.

Laser-induced oxidative labeling was initially conducted for both BR variants in their native purple membrane environment. As expected, extensive oxidation occurred at all three loop-exposed methionines (illustrated for T2 [M32] of L93M BR in Figure 3a). In contrast, hardly any labeling was observed for the buried Met residues, including the newly introduced residues M93 (Figure 3b) and M179 (Figure 3c).

SDS denaturation did not affect the extensive oxidation of the loop methionines M32 (Figure 3d), M68, and M163. In contrast, the denatured protein showed dramatically enhanced +16 Da labeling for peptide T5 of the L93M variant, whereas no indication of doubleoxidation (+32 Da) was found (Figure 3e). The fact that very similar data (not shown) were observed for peptide $\mathrm{T} 5$ of V179M already suggests that the labeling seen in Figure 3e reflects oxidation of the natural M118, rather than the substituted M93. This assertion was directly confirmed by MS/MS analysis of (T5 + 16) from L93M (Figure 4). CID yields unmodified y11 ions in both unlabeled (Figure 4a) and oxidized T5 (Figure

Table 1. Tryptic peptides of L93M BR and V179M BR. The N-terminal " $X$ " represents pyroglutamate [81]. Methionine residues are underlined

\begin{tabular}{|c|c|c|c|}
\hline Peptide & Sequence & Mass (Da) & $m / z$ \\
\hline T1 (1-30) & XAQITGRPEWIWLALGTALMGLGTLYFLVK & 3328.80 & 1110.61 \\
\hline T2 (31-40) & GMGVSDPDAK & 975.43 & 488.72 \\
\hline T3-4 (41-82) & $\begin{array}{l}\text { KFYAITTLVPAIAFTMYYSMLLGYGLTMVP } \\
\text { FGGEONPIYWAR }\end{array}$ & 4743.43 & 1186.87 \\
\hline \multirow[t]{2}{*}{ T5 (83-129) } & $\begin{array}{l}\text { For V179M BR: } \\
\text { YADWLFTTPLLLLDLALLVDADOGTILA } \\
\text { LVGADGIMIGTGLVGALTK }\end{array}$ & 4840.66 & 1614.56 \\
\hline & $\begin{array}{l}\text { For L93M BR: } \\
\text { YADWLFTTPLMLLDLALLVDADOGTILA } \\
\text { LVGADGIMIGTGLVGALTK }\end{array}$ & 4858.62 & 1620.55 \\
\hline T6-7 (130-159) & VYSYRFVWWAISTAAMLYILYVLFFGFTSK & 3641.88 & 1214.97 \\
\hline T7 (135-159) & FVWWAISTAAMLYILYVLFFGFTSK & 2973.55 & 992.19 \\
\hline T8 (160-172) & AESMRPEVASTFK & 1451.71 & 484.91 \\
\hline \multirow[t]{2}{*}{ T10-11 (176-225) } & $\begin{array}{l}\text { For V179M BR: } \\
\text { NVTMVLWSAYPVVWLIGSEGAGIVP } \\
\text { LNIETLLFMVLDVSAKVGFGLILLR }\end{array}$ & 5413.00 & 1354.26 \\
\hline & $\begin{array}{l}\text { For L93M BR: } \\
\text { NVTVVLWSAYPVVWLIGSEGAGIVP } \\
\text { LNIETLLFMVLDVSAKVGFGLILLR }\end{array}$ & 5381.03 & 1346.26 \\
\hline T11 (217-225) & VGFGLILLR & 986.63 & 494.32 \\
\hline T13 (228-248) & AIFGEAEAPEPSAGDGAAATS & 1917.86 & 959.94 \\
\hline
\end{tabular}




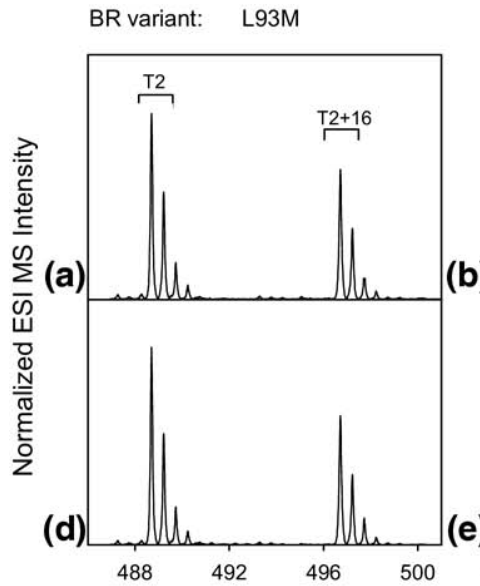

(b)

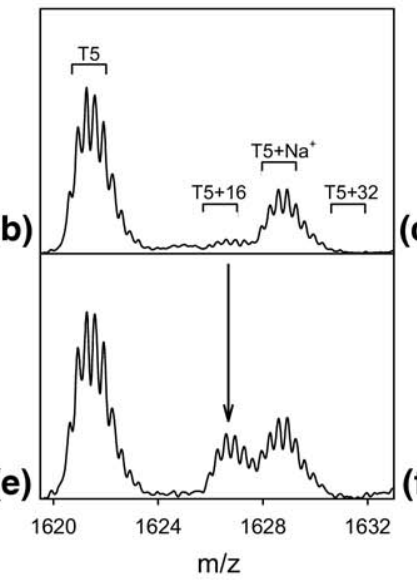

(c)

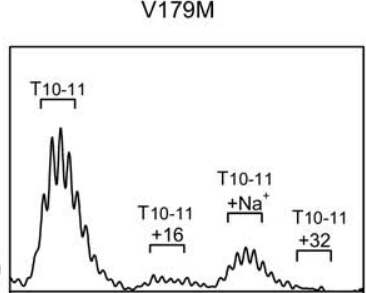

Figure 3. ESI-MS data for tryptic peptides T2 (a), (d) and T5 (b), (e) of L93M BR, and T10-11 of V179M BR (c), (f) after oxidative labeling. Panels (a)-(c) refer to data obtained for BR in its natural purple membrane environment. Panels (d)-(f) are for SDS-denatured protein. The vertical arrow in (e) highlights the formation of a +16 Da modification for T5 after SDS exposure.

$4 b)$. In contrast y12 and all the following fragment ions are shifted by $16 \mathrm{Da}$ for oxidized T5. These MS/MS data confirm that M118 gets oxidatively labeled in SDSdenatured L93M BR, whereas the newly introduced M93 remains protected. In addition, Figure $3 c$ and $f$ reveal that SDS denaturation affects neither the protection of M209, nor that of the substituted M179.
A comprehensive overview of the protein labeling behavior under native conditions and after SDS denaturation is obtained by considering the $F_{u}{ }^{\text {corr }}$ values of individual Met residues (Figure 5). Sites with $F_{u}{ }^{\text {corr }}$ values close to unity reflect a high degree of protection, whereas in the case of solvent accessible methionines $F_{u}{ }^{c o r r}<1$. For the conditions used here (average flow

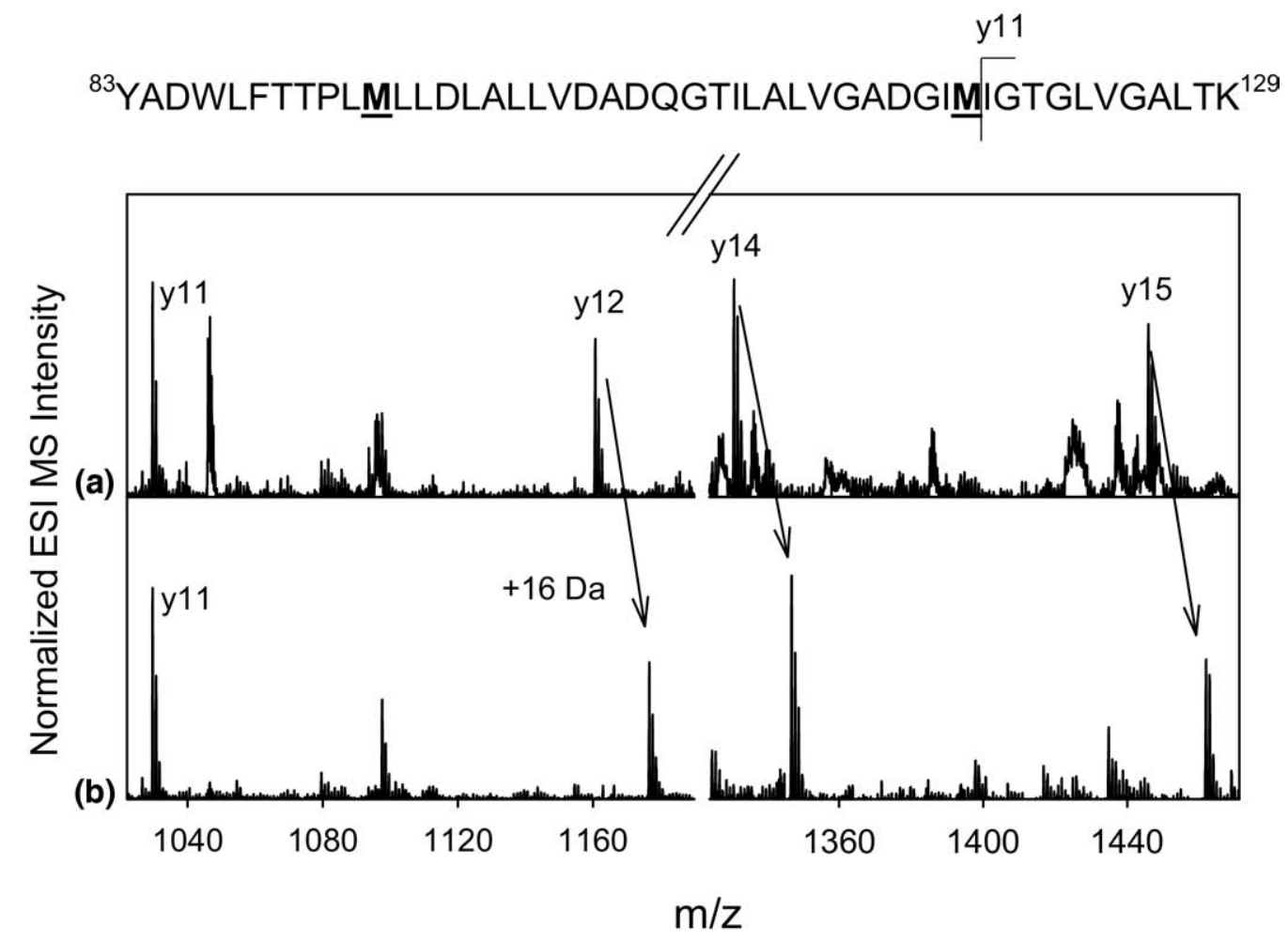

Figure 4. Partial MS/MS product ion spectra obtained after fragmentation of unlabeled T5 of L93M BR (a), and of the oxidized T5 + 16 Da (b) species. Shown at the top of the Figure is the sequence of T5. Arrows indicate +16 Da mass shifts due to oxidative labeling of M118. 


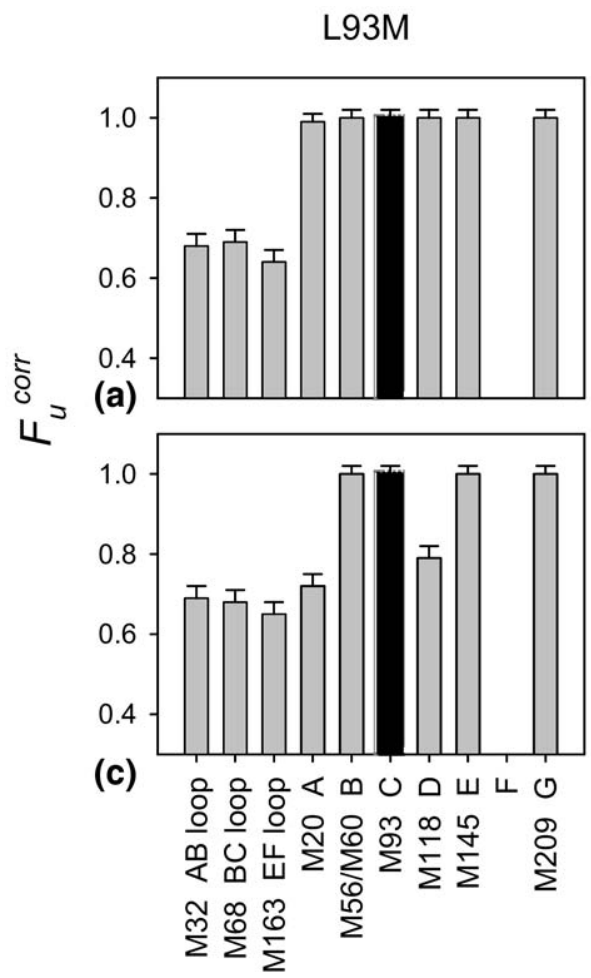

(b)
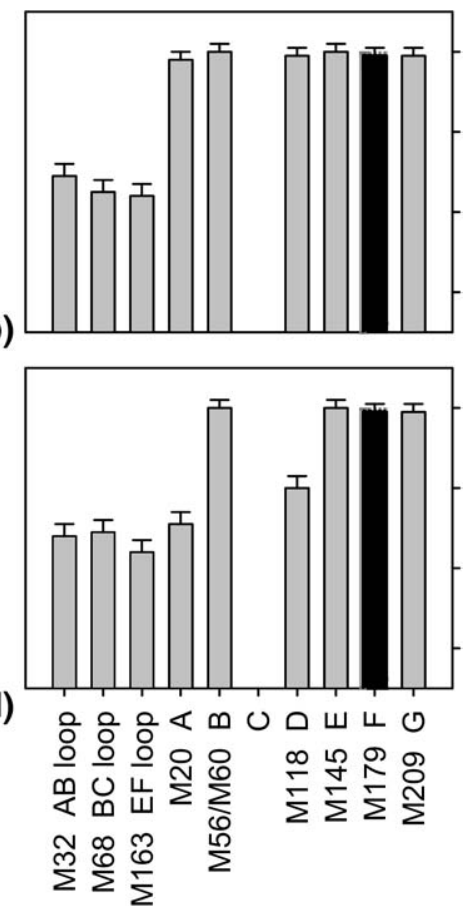

Figure 5. $F_{u}{ }^{\text {corr }}$ values of individual Met residues in native L93M BR (a), native V179M BR (b), and of the two protein variants after SDS denaturation $(\mathbf{c})$ and $(\mathrm{d})$. Highlighted in black are results for the L93M and V179M amino acid substitutions. Data for naturally occurring methionines are in gray.

velocity $8.5 \mathrm{~cm} \mathrm{~s}^{-1}$, laser pulse rate $16 \mathrm{~Hz}$, irradiation spot width $2 \mathrm{~mm}$, labeling intensity parameter $c=0.38$ [25] it can be estimated that $34 \%$ of the protein solution undergoes $\cdot \mathrm{OH}$ exposure, whereas $66 \%$ remain unirradiated. Thus, methionine residues that are completely solvent accessible should be characterized by $F_{u}{ }^{\text {corr }} \approx 0.66$. This estimate closely matches the value seen for M32, M68, and M163, which are located in the extramembrane loops of native BR. In contrast, all methionines situated in the seven transmembrane helices of native BR are protected from oxidation, with $F_{u}{ }^{\text {corr }} \approx 1$ (Figure 5a, b).

After SDS exposure the $F_{u}{ }^{\text {corr }}$ value of M20 [helix A] drops from unity to 0.72 . A pronounced decrease down to 0.79 also occurs for M118 [helix D] (Figure 5c, d). Except for these two changes, the oxidation patterns of the two BR variants are hardly affected by SDS exposure. All residues located in helices B, C, E, F, and G continue to be strongly protected with $F_{u}{ }^{\text {corr }}$ close to unity. Notably, this protection includes the engineered residues M93 and M179, which for the first time provide information on behavior of helices $C$ and $\mathrm{F}$, respectively.

\section{Structural Implications: BR in SDS}

The data of this study provide novel insights into the structural properties of SDS-denatured BR. From previous work it is known that SDS disrupts the native purple membrane and solubilizes individual protein molecules in monomeric form [69, 70]. Furthermore, SDS exposure results in hydrolysis of the Schiff base and release of the chromophore into the solvent [60].

The oxidative labeling data of Figure 5 confirm that helices A and D in SDS-denatured BR are largely unfolded [56] and likely extruded from the protein core, in a manner analogous to that proposed for other semi-unfolded membrane proteins [71]. Nonetheless, from our data it is also clear that the monomeric protein maintains a tightly folded core that is inaccessible to . OH (and therefore to water). This core encompasses the regions surrounding the naturally occurring methionines of helices B, E, and G, as well as parts of C and F that were probed here through methionine substitutions (M93 and M179). An earlier circular dichroism study found a residual helicity of $42 \%$ for SDS-denatured BR, down from a native state value of $74 \%$ [72]. The results presented here are consistent with a scenario where this residual helicity is caused by partially intact helices $\mathrm{B}$, C, E, F, and G. However, HDX measurements suggest that these helices are significantly more dynamic than in native BR. Specifically, it was found that the number of highly protected backbone hydrogens in SDS drops to one third of the native state value [60] (see also Figure $2 b)$. The oxidative labeling data presented here imply that the central regions of the helices where most methionines are located remain fairly stable, such that HDX must be predominantly mediated by helix fraying 
at the termini. Protected Met residues are either close to the helix center (M93, M145, M179) or close to the extracellular side (M56/60, M209, Figure 1). Thus, much of the helix dynamics responsible for the extensive HDX of the SDS state must occur on the cytoplasmic side. It is unfortunate that the spatial resolution of currently existing BR HDX data [68] is insufficient for directly confirming our view that the cytoplasmic side of SDSdenatured BR is more dynamic than the extracellular side. Nonetheless, additional support for this scenario comes from fluorescence spectroscopic data which show that all of the Trp residues close to the extracellular side maintain a nonpolar environment in SDS [56]. In addition, even for native BR it has been reported that the cytoplasmic side of the protein is more dynamic [73] and less completely covered in the hydrophobic membrane bilayer [38].

The nonpolar outside perimeter of the residual BCEFG protein core is expected to be laterally surrounded by tightly packed alkyl chains of the SDS detergent in a micellar fashion [45], replacing previously existing protein/lipid and protein/protein interactions. Water penetration into this lipophilic shell is minimal, as demonstrated by the lack of oxidative labeling for the substituted M179 which should be oriented towards the outside (Figure 1), i.e., facing the detergent alkyl chains.

\section{Conclusions}

The oxidative labeling data of the current study expand our previous findings $[56,60]$ on the structural properties of SDS-denatured BR. The introduction of two additional Met residues makes it possible to probe the solvent accessibility of this protein with a better coverage than previously possible. Out of the eleven methionines, eight are located in transmembrane regions, such that every BR helix is covered by at least one potential labeling site.

It is remarkable that $\cdot \mathrm{OH}$ labeling reveals significantly enhanced solvent accessibility for only two of the helices after SDS exposure, whereas changes in amide HDX protection are much more dramatic [60]. This behavior illustrates the complementarity between the two methods [1]. Covalent labeling strategies probe the solvent accessibility of reactive sites, whereas HDX monitors structural dynamics and the intactness of the H-bonding network [74].

From an analytical point of view, the permanent nature of protein covalent labels greatly facilitates the proteolytic mapping procedure. HDX experiments are considerably more challenging in this regard because back-exchange requires the digestion and LC separation steps to be completed in as little as $15 \mathrm{~min}$ [6]. The situation is particularly challenging for membrane proteins where digestion efficiencies under HDX conditions tend to be low [68], and where detergents often interfere with the analysis. It is therefore not surprising that membrane protein covalent labeling has become a fairly routine approach, whereas only a handful of HDX studies in this area have appeared over the past few years [28]. Luckily, however, several very recent studies indicate that rapid progress is now being made in the area of membrane protein HDX/MS [75-77].

The current work uses MetO formation as an easily identifiable covalent modification for monitoring the solvent accessibility of individual BR segments. This strategy is particularly suitable for membrane proteins because many of these species are methionine rich [78, 79]. Here we exploit the fact that $X \rightarrow M$ substitutions in membrane proteins tend to be structurally benign due to the medium size and mildly hydrophobic character of methionine [80]. In this way it is possible to engineer additional labeling sites into the protein, thereby enhancing the level of structural detail that is obtainable. In principle, it would be possible to conduct these studies on protein constructs that contain multiple substituted methionines. This work followed a more cautious strategy that minimizes the possibility of mutation-induced structural artifacts by studying one substitution at a time. The combination of protein engineering and oxidative labeling employed here should also be suitable for monitoring the structure and conformational transitions of other membrane proteins.

\section{Acknowledgments}

The authors acknowledge supported for this work by the Natural Sciences and Engineering Research Council of Canada (NSERC), the Canada Foundation for Innovation (CFI), the Canada Research Chairs Program, and The University of Western Ontario. The authors thank Professor Janos K. Lanyi (UC Irvine) for providing us with $H$. salinarum strains expressing the L93M and V179M BR variants.

\section{References}

1. Konermann, L.; Tong, X.; Pan, Y. Protein Structure and Dynamics Studied by Mass Spectrometry: H/D Exchange, Hydroxyl Radical Labeling, and Related Approaches. J. Mass Spectrom. 2008, 43, 10211036

2. Kaltashov, I. A.; Eyles, S. J. Mass Spectrometry in Biophysics; John Wiley and Sons, Inc.: Hoboken, NJ, 2005.

3. Sharon, M. How Far Can We Go with Structural Mass Spectrometry of Protein Complexes? J. Am. Soc. Mass Spectrom. 2010, 21, 487-500.

4. Wang, W.; Kitova, E. N.; Klassen, J. S. Influence of Solution and Gas Phase Processes on Protein-Carbohydrate Binding Affinities Determined by Nanoelectrospray Fourier Transform Ion Cyclotron Resonance Mass Spectrometry. Anal. Chem. 2003, 75, 4945-4955.

5. Kaltashov, I. A.; Abzalimov, R. R. Do Ionic Charges in ESI MS Provide Useful Information on Macromolecular Structure? J. Am. Soc. Mass Spectrom. 2008, 19, 1239-1246.

6. Engen, J. R. Analysis of Protein Conformation and Dynamics by Hydrogen/Deuterium Exchange MS. Anal. Chem. 2009, 81, 7870-7875.

7. Yu, E. T.; Hawkins, A.; Eaton, J.; Fabris, D. M. S. 3D Structural Elucidation of the HIV-1 Packaging Signal. Proc. Natl. Acad. Sci. U.S.A. 2008, 105, 12248-12253.

8. Schulz, D. M.; Ihling, C.; Clore, G. M.; Sinz, A. Mapping the Topology and Determination of a Low-Resolution Three-Dimensional Structure of the Calmodulin-Melittin Complex by Chemical Cross-Linking and High-Resolution FTICRMS: Direct Demonstration of Multiple Binding Modes. Biochemistry 2004, 43, 4703-4715.

9. Mendoza, V. L.; Vachet, R. W. Probing Protein Structure by Amino Acid-specific Covalent Labeling and Mass Spectrometry. Mass Spectrom. Rev. 2009, 28, 785-815.

10. Fitzgerald, M. C.; West, G. M. Painting Proteins with Covalent Labels: What's in the Picture? J. Am. Soc. Mass Spectrom. 2009, 20, 1193-1206.

11. Chen, H.; Schuster, M. C.; Sfyroera, G.; Geisbrecht, B. V.; Lambris, J. D. Solution Insights into the Structure of the Efb/C3 Complement Inhibi- 
tory Complex as Revealed by Lysine Acetylation and Mass Spectrometry. J. Am. Soc. Mass Spectrom. 2008, 19, 55-65.

12. Zhou, X.; Lu, Y.; Wang, W.; Borhan, B.; Reid, G. E. "Fixed Charge" Chemical Derivatization and Data Dependant Multistage Tandem Mass Spectrometry for Mapping Protein Surface Residue Accessibility. J. Am. Soc. Mass Spectrom. 2010, in press, doi:10.1016/j.jasms.2010.03.047.

13. McClintock, C.; Kertesz, V.; Hettich, R. L. Development of an Electrochemical Oxidation Method for Probing Higher Order Protein Structure with Mass Spectrometry. Anal. Chem. 2008, 80, 3304-3317.

14. Sharp, J. S.; Becker, J. M.; Hettich, R. L. Analysis of Protein Solvent Accessible Surfaces by Photochemical Oxidation and Mass Spectrometry. Anal. Chem. 2004, 76, 672-683.

15. Xu, G.; Chance, M. R. Hydroxyl Radical-Mediated Modification of Proteins as Probes for Structural Proteomics. Chem. Rev. 2007, 107, 3514-3543.

16. Maleknia, S. D.; Downard, K. Radical Approaches to Probe Protein Structure, Folding, and Interactions by Mass Spectrometry. Mass Spectrom. Rev. 2001, 20, 388-401.

17. Boys, B. L.; Kuprowski, M. C.; Noël, J. J.; Konermann, L. Protein Oxidative Modifications During Electrospray Ionization: Solution Phase Electrochemistry or Corona Discharge-Induced Radical Attack? Anal. Chem. 2009, 81, 4027-4034.

18. Lim, J.; Vachet, R. W. Development of a Methodology Based on Metal-Catalyzed Oxidation Reactions and Mass Spectrometry to Determine the Metal Binding Sites in Copper Metalloproteins. Anal. Chem. 2003, 75, 1164-1172.

19. Shcherbakova, I.; Mitra, S.; Beer, R. H.; Brenowitz, M. Fast Fenton Footprinting: A Laboratory-Based Method for the Time-Resolved Analysis of DNA, RNA, and Proteins. Nucleic Acids Res. 2006, 34, e48.

20. Watson, C.; Janik, I.; Zhuang, T.; Charvatova, O.; Woods, R. J.; Sharp, J. S. Pulsed Electron Beam Water Radiolysis for Submicrosecond Hydroxyl Radical Protein Footprinting. Anal. Chem. 2009, 81, 2496-2505.

21. Hambly, D. M.; Gross, M. L. Laser Flash Photolysis of Hydrogen Peroxide to Oxidize Protein Solvent-Accessible Residues on the Microsecond Timescale. J. Am. Soc. Mass Spectrom. 2005, 16, 2057-2063.

22. Aye, T. T.; Low, T. Y.; Sze, S. K. Nanosecond Laser-Induced Photochemical Oxidation Method for Protein Surface Mapping with Mass Spectrometry. Anal. Chem. 2005, 77, 5814-5822.

23. Stocks, B. B.; Konermann, L. Time-Dependent Changes in Side Chain Solvent Accessibility During Cytochrome $c$ Folding Probed by Pulsed Oxidative Labeling and Mass Spectrometry. J. Mol. Biol. 2010, 398, 362-373.

24. Gau, B. C.; Sharp, J. S.; Rempel, D. L.; Gross, M. L. Fast Photochemical Oxidation of Protein Footprints Faster than Protein Unfolding. Anal. Chem. 2009, 81, 6563-6571.

25. Konermann, L.; Stocks, B. B.; Czarny, T. Laminar Flow Effects During Laser-Induced Oxidative Labeling For Protein Structural Studies by Mass Spectrometry. Anal. Chem. 2010, 82, 6667-6674.

26. George, S. R.; O'Dowd, B. F.; Lee, S. P. G-Protein-Coupled Receptor Oligomerization and Its Potential for Drug Discovery. Nat. Rev. Drug Discov. 2002, 1, 808-820.

27. White, S. H. Biophysical Dissection of Membrane Proteins. Nature 2009, 459, 344-346.

28. Pan, Y.; Konermann, L. Membrane Protein Structural Insights from Chemical Labeling and Mass Spectrometry. Analyst 2010, 135, 11911200.

29. Orban, T.; Gupta, S.; Palczewski, K.; Chance, M. R. Visualizing Water Molecules in Transmembrane Proteins Using Radiolytic Labeling Methods. Biochemistry 2010, 49, 827-834.

30. Leite, J. F.; Cascio, M. Probing the Topology of the Glycine Receptor by Chemical Modification Coupled to Mass Spectrometry. Biochemistry 2002, 41, 6140-6148

31. Kelly, B. L.; Gross, A. Potassium channel Gating Observed with Site-directed Mass Tagging. Nat. Struct. Biol. 2003, 10, 280-284.

32. Weinglass, A. B.; Whitelegge, J. P.; Faull, K. F.; Kaback, H. R. Monitoring Conformational Rearrangement in the Substrate-Bing Site of a Membrane Transport Protein by Mass Spectrometry. J. Biol. Chem. 2004, 279, $41858-41865$

33. Leite, J. F.; Blanton, M. P.; Shahgholi, M.; Dougherty, D. A.; Lester, H. A. Conformation-Dependent Hydrophobic Photolabeling of the Nicotinic Receptor: Electrophysiology-Coordinated Photochemistry and Mass Spectrometry. Proc. Natl. Acad. Sci. U.S.A. 2003, 100, 13054-13059.

34. Smedley, J. G.; Sharp, J. S.; Kuhn, J. F.; Tomer, K. B. Probing the $\mathrm{pH}$-Dependent Prepore to Pore Transition of Bacillus anthracis Protective Antigen with Differential Oxidative Protein Footprinting. Biochemistry 2008, 47, 10694-10704.

35. Weinglass, A. B.; Whitelegge, J. P.; Hu, Y.; Verner, G. E.; Faull, K. F.; Kaback, H. R. Elucidation of Substrate Binding Interactions in a Membrane Transport Protein by Mass Spectrometry. EMBO J. 2003, 22, 1467-1477.

36. Wang, X.; Kim, S.-H.; Ablonczy, Z.; Crouch, R. K.; Knapp, D. R. Probing Rhodopsin-Transducin Interactions by Surface Modification and Mass Spectrometry. Biochemistry 2004, 43, 11153-11162.

37. Weinglass, A. B.; Soskine, M.; Vazquez, J.; Whitelegge, J. P.; Faull, K. F.; Kaback, H. R.; Schuldiner, S. Exploring the Role of a Unique Carboxyl Residue in EmrE by Mass Spectrometry. J. Biol. Chem. 2005, 280, 7487-7492.

38. Luecke, H.; Schobert, B.; Richter, H.; Cartailler, J.; Lanyi, J. K. Structure of Bacteriorhodopsin at 1.55 A Resolution. J. Mol. Biol. 1999, 291, 899-911.
39. Trimpin, S.; Deinzer, M. L. Solvent-Free MALDI-MS for the Analysis of a Membrane Protein Via the Mini Ball Mill Approach: Case Study of Bacteriorhodopsin. Anal. Chem. 2007, 79, 71-78.

40. Heberle, J.; Fitter, J.; Sass, H. J.; Büldt, G. Bacteriorhodopsin: The Functional Details of a Molecular Machine are Being Resolved. Biophys. Chem. 2000, 85, 229-248.

41. Subramaniam, S.; Hirai, T.; Henderson, R. From Structure to Mechanism: Electron Crystallographic Studies of Bacteriorhodopsin. Phil. Trans. $R$ Soc. Lond. A 2002, 360, 859-874.

42. Eisele, J. L.; Rosenbusch, J. P. In Vitro Folding and Oligomerization of a Membrane Protein. Transition of Bacterial Porin from Random Coil to Native Conformation. J. Biol. Chem. 1990, 265, 10217-10220.

43. Plumley, F. G.; Schmidt, G. W. Reconstitution of Chlorophyll a/b Light-Harvesting Complexes: Xanthophyll-Dependent Assembly and Energy Transfer. Proc. Natl. Acad. Sci. U.S.A. 1987, 84, 146-150.

44. Otzen, D. E. Folding of DsbB in Mixed Micelles: A Kinetic Analysis of the Stability of a Bacterial Membrane Protein. J. Mol. Biol. 2003, 330, 641-649.

45. Booth, P. J.; Clarke, J. Membrane Protein Folding Makes the Transition. Proc. Natl. Acad. Sci. U.S.A. 2010, 107, 3947-3948.

46. Huysmans, G. H. M.; Baldwin, S. A.; Brockwell, D. J.; Radford, S. E. The Transition State for Folding of an Outer Membrane Protein. Proc. Natl. Acad. Sci. U.S.A. 2010, 107, 4099-4104.

47. Surrey, T.; Schmid, A.; Jähnig, F. Folding and Membrane Insertion of the Trimeric $\beta$-Barrel Protein OmpF. Biochemistry 1996, 35, 2283-2288.

48. Booth, P. J.; Curnow, P. Membrane Proteins Shape Up: Understanding In Vitro Folding. Curr. Opin. Struct. Biol. 2006, 16, 480-488.

49. Skach, W. R. Cellular Mechanisms of Membrane Protein Folding. Nat. Struct. Mol. Biol. 2009, 16, 606-612.

50. Dobson, C. M. Protein Folding and Misfolding. Nature 2003, 426 884-890.

51. Gunasekaran, K.; Tsai, C.-J.; Kumar, S.; Zanuy, D.; Nussinov, R. Extended Disordered Proteins: Targeting Function with Less Scaffold. Trends Biochem. Sci. 2003, 28, 81-85.

52. Dyson, H. J.; Wright, P. E. Equilibrium NMR Studies of Unfolded and Partially Folded Proteins. Nat. Struct. Biol. 1998, 5, 499-503.

53. Michaux, C.; Pomroy, N. C.; Prive, G. G. Refolding SDS-Denatured Proteins by the Addition of Amphipathic Co-Solvents. J. Mol. Biol. 2008, 375, 1477-1488.

54. Curnow, P.; Booth, P. J. Combined Kinetic and Thermodynamic Analysis of a-Helical Membrane Protein Unfolding. Proc. Natl. Acad. Sci. U.S.A. 2007, 104, 18970-18975.

55. Renthal, R. An Unfolding Story of Helical Transmembrane Proteins Biochemistry 2006, 45, 14559-14566.

56. Pan, Y.; Brown, L.; Konermann, L. Mapping the Structure of an Integral Membrane Protein under Semi-Denaturing Conditions by LaserInduced Oxidative Labeling and Mass Spectrometry. J. Mol. Biol. 2009, 394, 968-981.

57. Pan, Y. Stocks, B. B. Brown, L. Konermann, L. Structural Characterization of an Integral Membrane Protein in its Natural Lipid Environment by Oxidative Methionine Labeling and Mass Spectrometry. Anal. Chem. 2009, 81, 28-35.

58. West, G. M.; Tucker, C. L.; Xu, T.; Park, S. K.; Han, X.; Yates, J. R. I. Fitzgerald, M. C. Quantitative Proteomics Approach for Identifying Protein-Drug Interactions in Complex Mixtures Using Protein Stability Measurements. Proc. Natl. Acad. Sci. U.S.A. 2010, 107, 9078-9082.

59. Whitelegge, J. P.; Halgand, F.; Souda, P.; Zabrouskov, V. Top-Down Mass Spectrometry of Integral Membrane Proteins. Exp. Rev. Proteom. 2006, 3, 585-596.

60. Pan, Y.; Brown, L.; Konermann, L. Hydrogen/Deuterium Exchange Mass Spectrometry and Optical Spectroscopy as Complementary Tools for Studying the Structure and Dynamics of a Membrane Protein. Int. J. Mass Spectrom. 2010, in press, doi:10.1016/j.ijms.2010.04.011.

61. Buxton, G. V.; Greenstock, C. L.; Helman, W. P.; Ross, A. B. Critical Review of Rate Constants for Reactions of Hydrated Electrons, Hydrogen Atoms, and Hydroxyl Radicals $(\cdot \mathrm{OH} / \cdot \mathrm{O})$ in Aqueous Solution. I. Phys. Chem. Ref. Data 1988, 17, 513-886.

62. Tong, X.; Wren, J. C.; Konermann, L. Effects of Protein Concentration on the Extent of $\gamma$-Ray-Mediated Oxidative Labeling Studied by Electrospray Mass Spectrometry. Anal. Chem. 2007, 79, 6376-6382.

63. Xu, G.; Kiselar, J.; He, Q.; Chance, M. R. Secondary Reactions and Strategies to Improve Quantitative Protein Footprinting. Anal. Chem. 2005, 77, 3029-3037.

64. Saladino, J.; Liu, M.; Live, D.; Sharp, J. S. Aliphatic Peptidyl Hydroperoxides as a Source of Secondary Oxidation in Hydroxyl Radical Protein Footprinting. J. Am. Soc. Mass Spectrom. 2009, 20, 1123-1126.

65. Wang, J.; Heyes, C. D.; El-Sayed, M. A. Refolding of Thermally Denatured Bacteriorhodopsin in Purple Membrane. J. Phys. Chem. 2002, 106, 723-729.

66. Richter, H.; Needleman, R.; Kandori, H.; Maeda, A.; Lanyi, J. K. Relationship of Retinal Configuration and Internal Proton Transfer at the End of the Bacteriorhodopsin Photocycle. Biochemistry 1996, 35, 15461-15466.

67. Kandori, H.; Yamazaki, Y.; Hatanaka, M.; Needleman, R.; Brown, L. S. Richter, H.; Lanyi, L. K.; Maeda, A. Time-Resolved Fourier Transform Infrared Study of Structural Changes in the Last Steps of the Photocycles of Glu-204 and Leu-93 Mutants of Bacteriorhodopsin. Biochemistry 1997, 36, 5134-5141. 
68. Joh, N. H.; Min, A.; Faham, S.; Whitelegge, J. P.; Yang, D.; Woods, V. L.; Bowie, J. U. Modest Stabilization by Most Hydrogen-Bonded SideChain Interactions in Membrane Proteins. Nature 2008, 453, 1266-1270.

69. London, E.; Khorana, H. G. Denaturation and Renaturation of Bacteriorhodopsin in Detergents and Lipid-Detergent Mixtures. J. Biol. Chem. 1982, 257, 7003-7011.

70. Torres, J.; Sepulcre, F.; Padros, E. Conformational Changes in Bacteriorhodopsin Associated with Protein-protein Interactions: A Functional $\alpha \mathrm{I}-\alpha \mathrm{II}$ Helix Switch? Biochemistry 1995, 34, 16320-16326.

71. Hamasaki, N.; Abe, Y.; Tanner, M. J. A. Flexible Regions within the Membrane-Embedded Portions of Polytopic Membrane Proteins. Biochemistry 2002, 41, 3852-3854.

72. Riley, M. L.; Wallace, B. A.; Flitsch, S. L.; Booth, P. J. Slow $\alpha$-Helix Formation During Folding of a Membrane Protein. Biochemistry 1997, 36, 192-196

73. Grigorieff, N.; Ceska, T. A.; Downing, K. H.; Baldwin, J. M.; Henderson, $R$. Electron-Crystallographic Refinement of the Structure of Bacteriorhodopsin. J. Mol. Biol. 1996, 259, 393-421.

74. Chetty, P. S.; Mayne, L.; Lund-Katz, S.; Stranz, D. D.; Englander, S. W.; Phillips, M. C. Helical Structure and Stability in Human apo-Lipoprotein A-I by Hydrogen Exchange and Mass Spectrometry. Proc. Natl. Acad. Sci. U.S.A. 2009, 106, 19005-19010.

75. Hebling, C. M.; Morgan, C. R.; Stafford, D. W.; Jorgenson, J. W.; Rand, K. D.; Engen, J. R. Conformational Analysis of Membrane Proteins in
Phospholipid Bilayer Nanodiscs by Hydrogen Exchange Mass Spectrometry. Anal. Chem. 2010, in press, doi: 10.1021/ac100962c.

76. Zhang, X.; Chien, E. Y. T.; Chalmers, M. J.; Pascal, B. D.; Gatchalian, J.; Stevens, R. C.; Griffin, P. R. Dynamics of the $\beta 2$-Adrenergic G-Protein Coupled Receptor Revealed by Hydrogen/Deuterium Exchange. Anal. Chem. 2010, 82, 1100-1108.

77. Rey, M.; Mrzek, H.; Pompach, P.; Novk, P.; Pelosi, L.; Brandolin, G.; Forest, E.; Havlek, V.; Man, P. Effective Removal of Nonionic Detergents in Protein Mass Spectrometry, Hydrogen/Deuterium Exchange, and Proteomics. Anal. Chem. 2010, 82, 5107-5116.

78. Yu, Y.; Gilar, M.; Gebler, J. C. A Complete Peptide Mapping of Membrane Proteins: A Novel Surfactant Aiding the Enzymatic Digestion of Bacteriorhodopsin. Rapid Commun. Mass Spectrom. 2004, 18, $711-715$.

79. Ablonczy, Z.; Kono, M.; Crouch, R. K.; Knapp, D. R. Mass Spectrometric Analysis of Integral Membrane Proteins at the Subnanomolar Level: Application to Recombinant Photopigments. Anal. Chem. 2001, 73 , 4774-4779.

80. Kyte, J.; Doolittle, R. A Simple Method for Displaying the Hydropathic Character of a Protein. J. Mol. Biol. 1982, 157, 105-132.

81. Hufnagel, P.; Schweiger, U.; Eckerskorn, C.; Oesterhelt, D. Electrospray Ionization Mass Spectrometry of Genetically and Chemically Modified Bacteriorhodopsin. Anal. Biochem. 1996, 243, 46-54. 